\title{
Thermal Conductivity and Thermal Diffusivity of Slime Mold (Physarum Polycephalum)
}

\author{
Syou MAKI ${ }^{1 *}$, Shigeru KURODA², Seiji FUJIWARA ${ }^{3}$, Seiichi TANAKA ${ }^{3}$, Eka ERZALIA ${ }^{3}$, Mizuki KATO ${ }^{3}$, \\ Katsumasa $\mathrm{HIGO}^{3}$, Toshiaki ARATA ${ }^{4}$ and Toshiyuki NAKAGAKI ${ }^{5}$ \\ ${ }^{1}$ Institute of Frontier Science and Technology, Okayama University of Science, Japan \\ ${ }^{2}$ Faculty of Software and Information Technology, Aomori University, Japan \\ ${ }^{3}$ Department of Mechanical Engineering, National Institute of Technology, Akashi College, Japan \\ ${ }^{4}$ Cell Function Lab., Graduate School of Science, Osaka City University, Japan \\ ${ }^{5}$ Research Institute for Electronic Science, Hokkaido University, Japan \\ Corresponding author: Syou MAKI, Institute of Frontier Science and Technology, Okayama University of Science 1-1 Ridai-cho, \\ Kita-ku, Okayama, 700-0005 Japan
}

\section{ARTICLE INFO}

Received: 慧 October 10, 2020

Published: 慧 October 22, 2020

Citation: Syou MAKI, Shigeru KURODA, Seiji FUJIWARA, Seiichi TANAKA, Eka ERZALIA, Mizuki KATO, Katsumasa HIGO, Toshiaki ARATA, Toshiyuki NAKAGAKI. Thermal Conductivity and Thermal Diffusivity of Slime Mold (Physarum Polycephalum). Biomed J Sci \& Tech Res 31(3)-2020. BJSTR. MS.ID.005090.

\section{ABSTRACT}

We measured the thermal conductivity $(\lambda)$ and thermal diffusivity $(\alpha)$ of a myxomycete (slime mold) by the transient short-hot wire method. The measurements were conducted two times with temperatures varying from 277 to $300 \mathrm{~K}$. In the results, $\lambda$ $=0.489-0.572(\mathrm{~W} / \mathrm{m} \cdot \mathrm{K})$, and $\alpha=8.36 \times 10^{-8}-2.48 \times 10^{-7}\left(\mathrm{~m}^{2} / \mathrm{s}\right)$. The thermal properties of slime molds are close to those of water. In particular, the $\lambda$ is similar to that of biological materials (cells, human blood and plasma), and slightly different from that of some kinds of organic materials (lysozyme crystals, wheat, apple, and tomato), and evidently different from inorganic substances (sand and soil).

Keywords: Transient Short-Hot Wire Method; Myxomycetes; Biological Materials; Thermal Property

\section{Introduction}

Myxomycetes (slime molds) are amoeba-like eukaryotes classified as large multinuclear unicellular organisms and have the peculiarities of multicellular organisms. These strange features, e.g., plant-like characteristics and animal-like behaviors, have been attracting biological research interest for a long time [1-3]. Nakagaki et. al., recently discovered an interesting behavior of slime mold; that is, its dietary action can diversify to an optimized network $[4,5]$, but why and how such a mysterious network, a so called "slime mold computer", is realized has not been explained at all. We suspect that this network is controlled by some unknown sensory organs that perceive temperature and humidity in the surrounding environment, because we already know that slime molds have thermotactic [2, 6-9]. However, the thermal properties of slime molds have not been examined. We think that biophysical data of slime molds would contribute fundamentally and instructively to advances in discussions about the process of such a smart network formation. In this study, the thermal conductivity and thermal diffusivity of slime mold were measured by the technique of transient short-hot wire method [10-12].

\section{Sample}

The slime mold we used was Physarum polycephalum ( $P$. polycephalum), which is known as one of the representative morphobacteriums inhabiting various parts of the world. $P$. polycephalum prefers a cool and humid environment in the shade, such as fallen leaves on the forest floor and the surface of decayed trees. (Figure 1) is a photograph of $P$. polycephalum growing on a gelatinous medium. As shown, the bright yellow body is convenient for visual observation. 


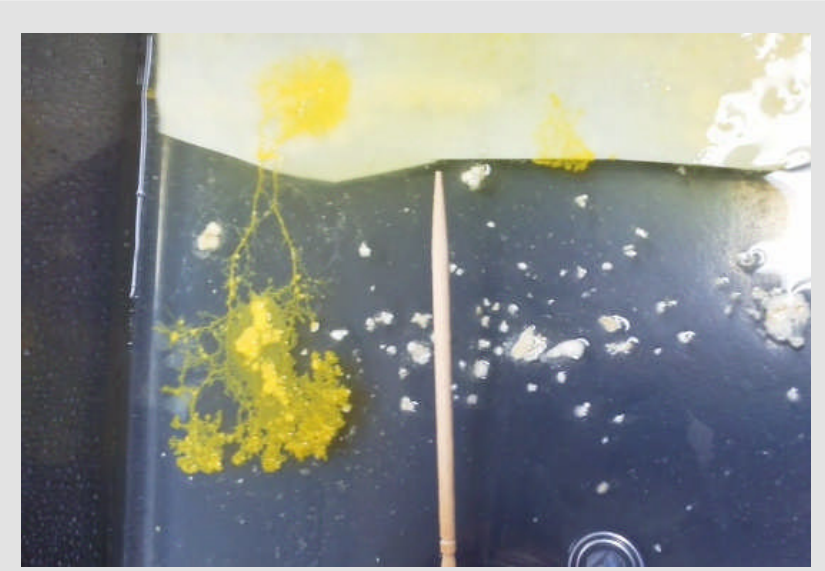

Figure 1: Myxomycetes (Physarum polycephalum) on the agarose gel medium

\section{Equipment}
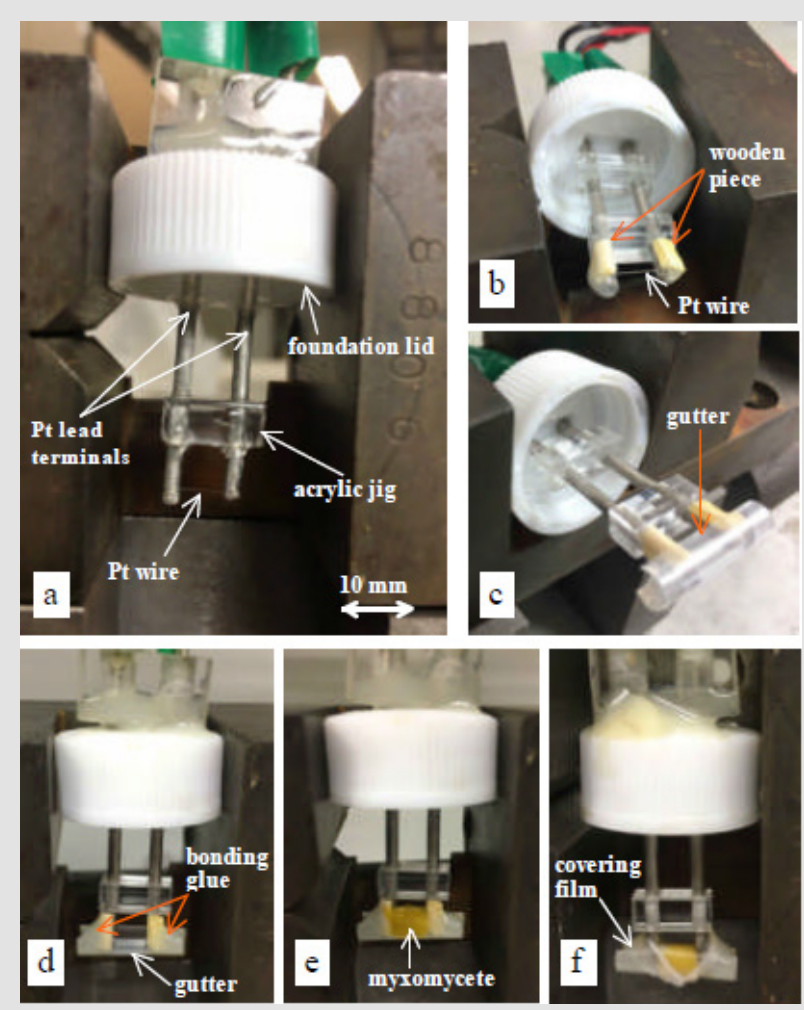

Figure 2: Transient short-hot-wire probe made of Pt.

The transient short-hot wire method has the capability of simultaneously measuring the thermal conductivity and thermal diffusivity of samples with a small volume. Various kinds of rare substances, i.e., refrigerants [12], molten polymers [13], molten carbonates [14], and protein crystals [11,15], have been investigated by this method. (Figure 2a) shows the probe used in this method. As shown in (Figure 2b), the wire was made of platinum (Pt) with a diameter of $30 \mu \mathrm{m}$ (NILACO Co. Ltd) and a length of $7.2 \mathrm{~mm}$. This was welded to the ends of Pt lead terminals and was horizontally bridged there. Using the same material for the wire and the terminals allowed us to avoid the See beck effect that happens when a heating power is instantly supplied to the probe. The lead terminals (diameter $2.0 \mathrm{~mm}$ ) were connected by acrylic jigs and fixed to the foundation lid. A voltage application line and a voltage measurement line were connected to the other end of the terminals. (Figure 3) is a schematic illustration of the electric circuit, including the probe. The probe part is identified by the broken line. The circuit has a DC power supply (6240B, ADCMT Co. Ltd.), an AD converter (USB-2408, Measurement Computing Co., Ltd), and a standard resistance of $10 \Omega$ (2792A05, Yokogawa Test \& Measurement Co., Ltd.). The DC power supply was modulated to use the random sweep mode in the measurement.

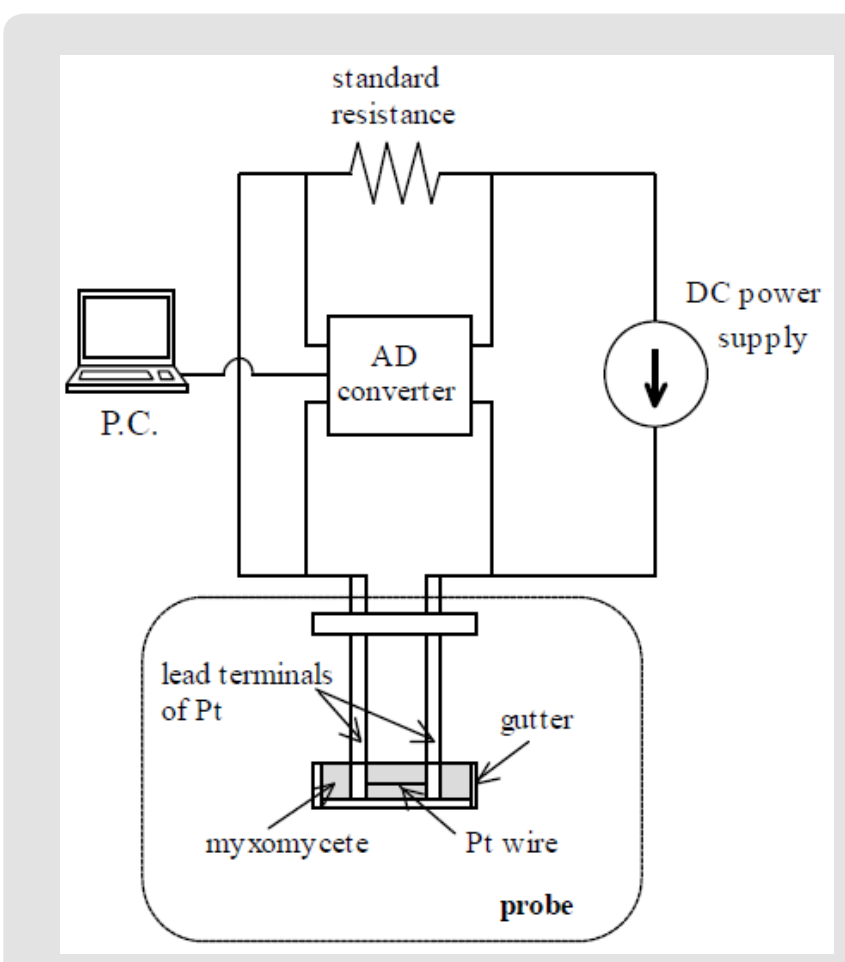

Figure 3: Schematic illustration of the electric circuit. The broken line shows the part of the probe.

The sampling rate and the resolution of the $\mathrm{AD}$ converter were set to $100 \mathrm{~Hz}$ and 24 bits, respectively. In the first stage of the measurement, a small current was supplied to the probe for 5 seconds in order to detect the temperature of the samples, then a large electric current (heating current) was supplied continuously. Prior to the measurement, the volume of the current and the heating time were adjusted with pure water so that only the wire part was locally heated and the rise in the temperature of the lead terminals became negligibly small. The electric current and the heating time were decided as $120 \mathrm{~mA}$ and $5 \mathrm{~s}$, respectively. The voltage of the probe was recorded during the measurement, and the transient rise in the temperature of the wire was automatically calculated by the PC. As a consequence, we could measure the thermal properties of the samples by analyzing the gradient and the intercept of the temperature response, the practical procedure of which is explained in the next section. 


\section{Measuring Principal}

(Figure 4) shows the transient response rise in temperature of the wire $\left(d T_{w}\right)$ when the heating current is supplied. The $d T_{\mathrm{w}}$ increases against the current-flow time ( $\mathrm{t}$ ) and is linearly approximated as follows:

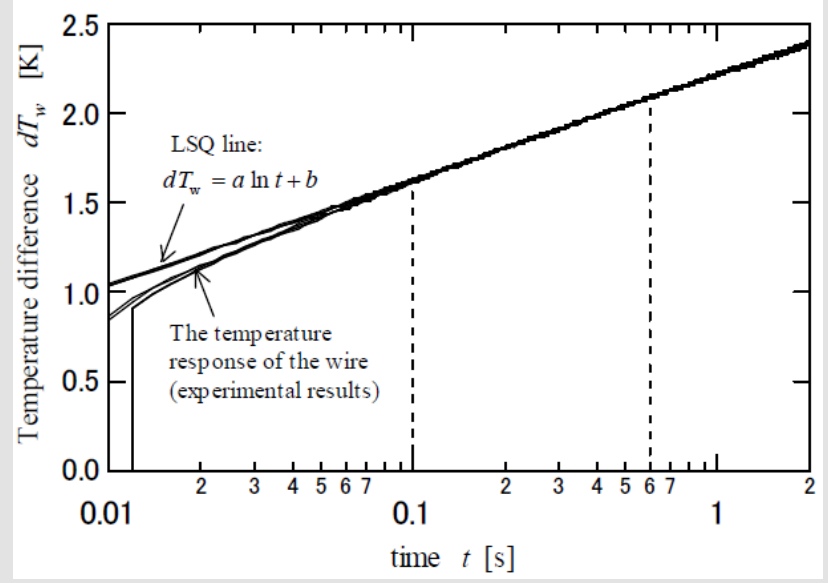

Figure 4: The transient response of the rise in temperature of the wire when the heating current is instantly supplied.

$$
d T_{w}=a \ln t+b .
$$

The logarithmic relationship between $d T_{\mathrm{w}}$ and $\mathrm{t}$ in Eq. 1 are theoretically presented by the principle by which the heat transfer from the axisymmetric heat source to the circumstance is provided by a logarithmic function with respect to radial distance [16]. The coefficient and the intercept $\mathrm{b}$ are experimentally determined by the use of the least-squares (LSQ) fitting of the response. One of the major technical advantages of the transient short-hot wire method is that numerical computation is jointly utilized to calibrate the mechanical constant. The calibration was conducted by using pure water. This measuring procedure has been described elsewhere $[10,11,15]$. Finally, the thermal conductivity $(\lambda)(\mathrm{W} / \mathrm{m} \cdot \mathrm{K}))$ and the thermal diffusivity $(\alpha)\left(\mathrm{m}^{2} / \mathrm{s}\right)$ of the samples are obtained as follows.

$$
\lambda=q_{v} r_{i}^{2} \frac{A}{a}, \alpha=r_{i}^{2} \exp \left(\frac{b}{a}-\frac{B}{A}\right)
$$

where, qv and ri, are the volumetric heat generation and the short-hot wire radius, respectively. Both $\mathrm{A}$ and $\mathrm{B}$ were the parameters decided by the numerical computation.

\section{Experiments}

In order to contact the wire onto the $P$. polycephalum, we utilized a small "gutter" as shown in (Figures 2c \& 2d). This was made of a polypropylene straw bisected in the axial direction and then horizontally fixed to the lead terminals with a bonding glue, as shown in (Figure 2D). The wire and the gutter were prevented from contacting each other by a small piece of wood that was inserted between the gutter and the terminals and which served as an insulating material, as shown in (Figure 2B). Owing to this improvement, the wire could be located in the center of the gutter. As to the LSQ fitting to obtain the $a$ and $b$, the data range was set from 0.1 to $0.6 \mathrm{~s}$, where the response became linear. The slime mold was utilized when it was active. On the day before the measurement, dried P. polycephalum was placed on an agarose gel and lightly sprayed with water to induce germination. It was then put in a darkroom with a constant temperature of $20^{\circ} \mathrm{C}$. The $P$. polycephalum cultured on the gel vividly about 12 hours later. After it was carefully placed in the gutter (Figure 2e), it was completely covered with a film to keep it from drying (Figure 2f). Finally, the probe, represented the illustration by the part outlined with a broken line in (Figure 3), was installed in an incubator and kept at a steady temperature.

Measurements were conducted two times in order to confirm reproducibility. The first measurement shall be named as Exp.1, and the second one as Exp.2. Exp.1 was carried out by varying the temperature to 285.2, 293.2, and $300.2 \mathrm{~K}$. Exp.2 was done at temperatures of $277.2,285.2,293.2$, and $299.9 \mathrm{~K}$. In both experiments, the measurements were independently performed 5 times at the same temperatures, with the intervals set to 3 minutes or more longer for each measurement.

\section{Results}

(A)

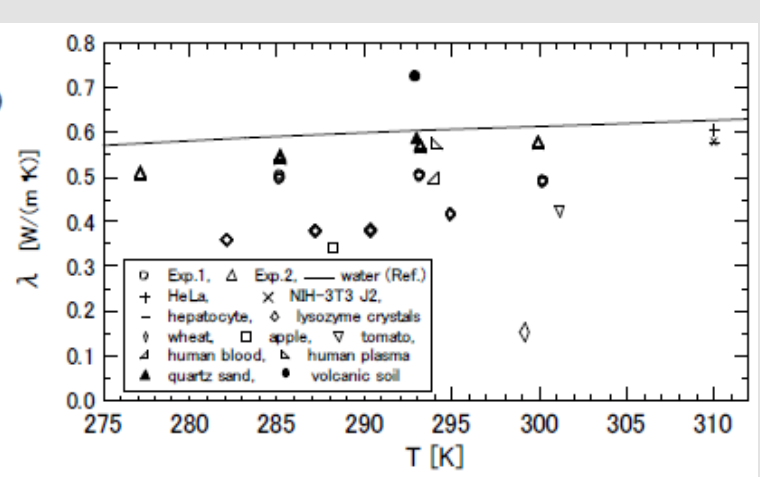

(B)

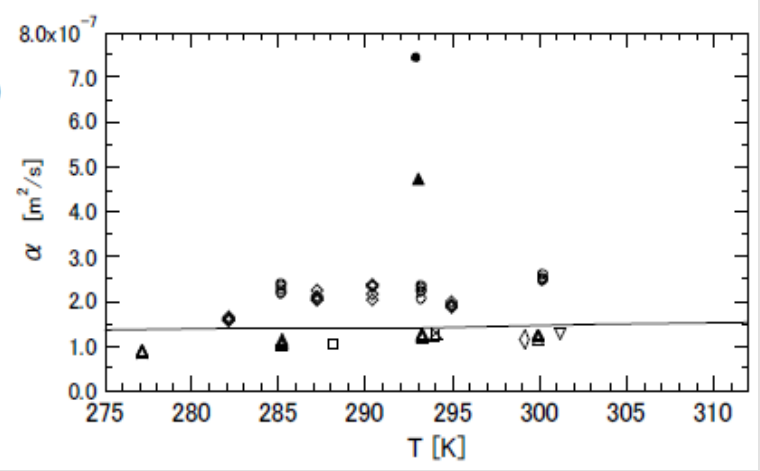

Figure 5: Thermal properties of $\lambda$ and $\alpha$

(A) Thermal conductivity,

(B) Thermal diffusivity 
All the results of $\lambda$ and $\alpha$ are exhibited in (Figures 5A \& 5B), respectively. The data of Exp. 1 and Exp. 2 are shown by the circles $(0)$ and the squares $(\Delta)$, respectively. The bold line indicates the reference data of water [17]. The averaged values and the coefficients of variation (C.V.) of Exp. 1 and Exp. 2 are summarized in (Table 1). The thermal conductivities of three kinds of biological cells of HeLa (0.604 W/( $\cdot$ - K), C.V. 0.83, crucifix), NIH-3T3 J2 (0.579 W/( m • K), C.V. 0.79 , X cross), and hepatocyte cells $(0.575 \mathrm{~W} /(\mathrm{m} \cdot \mathrm{K}), \mathrm{C} . \mathrm{V} .0 .87$, minus) are presented in (Figure 5A) as references [18], although

Table 1: Summary of the results. the thermal diffusivity of these cells was not measured. In (Figure 5) we also exhibit the data of wheat at $299.15 \mathrm{~K}$ (spindle-shaped diamond) [19] apple at $288.15 \mathrm{~K}$ (square) [20], tomato at $301.15 \mathrm{~K}$ (inverted triangle) [21], human blood at $294 \mathrm{~K}$ (right off-centered triangle) [22], human plasma at $294 \mathrm{~K}$ (left off-centered triangle) [22], hen egg white lysozyme crystals (diamond) [15], quartz sand (filled triangle) [23], and volcanic soil (filled diamond) [24]. The percentage of water content of the wheat, apple, and tomato was 8.4, 84.7, and $92.3 \%$, respectively. The data of the human blood and human plasma were measured with a thermistor.

\begin{tabular}{|c|c|c|c|c|c|}
\hline \multirow{2}{*}{ Temperature (K) } & \multicolumn{2}{|c|}{$\lambda(\mathbf{W} /(\mathbf{m} . \mathbf{K}))$} & \multicolumn{2}{c|}{$\boldsymbol{\alpha}\left(\mathrm{m}^{2} / \mathbf{s}\right)$} & \multicolumn{2}{c|}{ Average } \\
\cline { 2 - 6 } & 285.15 & Average & C.V. & $2.25 \times 10^{-7}$ & $4.48 \times 10^{-2}$ \\
\hline Exp. 1 & 293.15 & 0.497 & $6.45 \times 10^{-3}$ & $2.20 \times 10^{-7}$ & $4.75 \times 10^{-2}$ \\
\hline & 300.15 & 0.501 & $2.12 \times 10^{-3}$ & $2.48 \times 10^{-7}$ & $2.49 \times 10^{-2}$ \\
\hline & 277.15 & 0.489 & $4.65 \times 10^{-3}$ & $8.36 \times 10^{-8}$ & $3.16 \times 10^{-2}$ \\
\hline Exp. 2 & 285.15 & 0.505 & $4.27 \times 10^{-3}$ & $1.03 \times 10^{-7}$ & $4.24 \times 10^{-2}$ \\
\hline & 293.2 & 0.539 & $7.87 \times 10^{-3}$ & $1.20 \times 10^{-7}$ & $2.82 \times 10^{-2}$ \\
\hline & 299.9 & 0.565 & $4.02 \times 10^{-3}$ & $1.17 \times 10^{-7}$ & $2.85 \times 10^{-2}$ \\
\hline
\end{tabular}

The data of the lysozyme crystals were measured by the transient short-hot wire method, and the measurement temperature was varied to 282.1, 287.2, 290.4, and 294.9 K. This measurement was realized by the technique of magneto Archimedes levitation $[25,26]$, hence the crystals were orientated so that the c-axis became perpendicularly crossed to the axial direction of the wire. The $\lambda$ of the quartz sand and volcanic soil was measured at 293 $\mathrm{K}$, and other reports clarified that the densities ( $\rho$ ) of quartz sand and volcanic soil at $293 \mathrm{~K}$ were 1750 and $1160 \mathrm{~kg} / \mathrm{m}^{3}$, respectively. Since the specific heat ( $C$ ) of the quartz sand and the volcanic soil at $298 \mathrm{~K}$ are known to be 0.71 and $0.84 \mathrm{~kJ} /(\mathrm{kg} \cdot \mathrm{K})$, respectively, the $\alpha$ of those at $293 \mathrm{~K}$ were approximated as $4.68 \times 10^{-7}$ and $7.40 \times$ $10^{-7} \mathrm{~m}^{2} / \mathrm{s}$, respectively, by using the relation of $\alpha=\lambda /(\rho \cdot C)$. The $\lambda$ and $\lambda$ of silica glass at $300 \mathrm{~K}$ are $1.38 \mathrm{~W} /(\mathrm{m} \cdot \mathrm{K})$ and $9.06 \times$ $10^{-7} \mathrm{~m}^{2} / \mathrm{s}$, respectively [27-29]. Hence, they are plotted outside the specific area of (Figure 5) The $\lambda$ and $\alpha$ of orange at $288.15 \mathrm{~K}$ were $0.415 \mathrm{~W} /(\mathrm{m} \cdot \mathrm{K})$ and $1.26 \times 10^{-7} \mathrm{~m}^{2} / \mathrm{s}$, respectively [30]. Similarly, the $\lambda$ and $\alpha$ of grapefruit at $288.15 \mathrm{~K}$ were $0.398 \mathrm{~W} /(\mathrm{m} \cdot \mathrm{K})$ and $1.21 \times 10^{-7} \mathrm{~m}^{2} / \mathrm{s}$, respectively [30]. Since the properties of orange and grapefruit are almost equal to those of apple, we did not exhibit them in (Figure 5).

\section{Discussion}

From the relationships between the measurement properties of the slime mold and other substances, the data of the slime mold were plotted close to those of human blood and human plasma. The thermal conductivities of three kinds of biological cells were located at almost the same points as the extrapolated data of the slime mold. The data of the slime mold and these cells were similar in the point that the values of thermal conductivity were slightly smaller than that of water. In the measurement accuracy, the C.V. of slim molds became much smaller than those of three kinds of biological cells. This indicates that the transient short-hot wire method is suitable for detecting the thermal properties of microbial tissues such as slime molds. Temperature dependence of $\lambda$ and $\alpha$ of slime molds was not found clearly although the data series of them were slightly varied as similar to those of water. The thermal conductivity of the slime mold was between the data of water and other biological data (lysozyme crystals, tomato, and apple), while the properties of the inorganic substance of volcanic soil differed widely from the organic ones. This suggests that when the slime molds move on the ground the effect of heat transfer on the ground is different from that on an organic substance. This may reflect why slime molds prefer to inhabit fallen leaves and bare trees. In other words, thermophysical properties may affect on the behavior of microorganisms such as slime molds.

\section{Conclusion}

In summary, we found that the thermal properties of slime mold are close to those of water; in particular, the thermal conductivity is similar to that of biological materials (cells, human blood and plasma), and is slightly different from some kinds of organic materials (lysozyme crystals, wheat, apple, and tomato), and is evidently different from inorganic substances (sand and soil). The quantitative data we detected will be useful for the future studies on slime molds' behavior, if they would be affected by the thermal properties. The measurement of thermal property will be the first step to progress a biometeorological approach not only of slime 
molds, but also in the field of fungal biology.

\section{Acknowledgement}

We received valuable advice from Prof. Yoshifumi Tanimoto. We would like to express our deepest gratitude for all this support.

\section{Funding}

This research was funded by many grants of MEXT/JSPS, KAKENHI (grant number JP15K04669, JP17K06215, JP17K14612, JP20K04335), and the Science Research Promotion Fund (2018), and the Promotion and Mutual Aid Corporation for Private Schools of Japan.

\section{References}

1. Kamiya N (1940) The control of protoplasmic streaming. Science 92: 462-463.

2. Bonner JT, Clarke WW Jr, Neely CL Jr, Slifkin MK (1950) The orientation to light and the extremely sensitive orientation to temperature gradients in the slime mold Dictyostelium discoideum. J Cell Comp Physiol 36: 149-158.

3. Miller DM, Anderson JD, Abbot BC (1968) Potentials and ionic exchange in slime mold plasmodia, Comparative Biochem. Physiol 27(3): 633-646.

4. Tero A, Kobayashi R, Nakagaki T (2007) A mathematical model for adaptive transport network in path finding by true slime mold. J Theore Biol 244(4): 553-564.

5. Tanaka Y, Nakagaki T (2011) Cellular computation realizing intelligence of slime mold Physarum Polycephalum. J Comput Theore Nanosci 8(3): 383-390.

6. Tso WW, Mansour TE (1975) Thermotaxis in a slime mold, Physarum polycephalum. Behavioral Biology 14 (4): 499-504.

7. Poff KL, Skokut M (1977) Thermotaxis by pseudoplasmodia of Dictyostelium discoideum. Proc Natl Acad Sci 74: 2007-2010.

8. Whitaker BD, Poff KL (1980) Thermal adaptation of thermosensing and negative thermotaxis in Dictyostelium. Exp Cell Res 128: 87-93.

9. Dusenbery DB (1988) Avoided temperature leads to the surface: Computer modeling of slime mold and nematode thermotaxis. Behavi Ecol Sociobiol 22: 219-223.

10. Fujii M, Zhang X, Imaishi N, Fujiwara S, Sakamoto T (1997) Simultaneous measurements of thermal conductivity and thermal diffusivity of liquids under microgravity conditions. Int J Thermophys 18: 327-339.

11. Fujiwara S, Maki S, Maekawa R, Tanaka S, Hagiwara M (2017) Measurements of thermal conductivity and thermal diffusivity of hen egg-white lysozyme crystals and its solution using the transient short hot wire method. Int J Thermophys 38 (8): 123.

12. Tomimura T, Maki S, Zhang X, Fujii M (2004) Measurements of thermal conductivity and thermal diffusivity of alternative refrigerants in liquid phase with a transient short-hot-wire method. Heat Transf Asian Res 33 (8): 540-552
13. Zhang X, Mikeda S, Wicaksono H, Fujiwara S, Fujii M(2001) Measurements of thermal conductivity and thermal diffusivity of polymers. Proc. of the $6^{\text {th }}$ Asian Thermophysical Properties Conference, Guwahati, India, 1: 3640 .

14. Zhang X, Wicaksono H, Fujiwara S, Fujii M (2002) Accurate measurements of thermal conductivity and thermal diffusivity of molten carbonates. High Temp High Pressu 34: 617-625.

15. Maki S, Fujiwara S, Tanaka S, Erzalia E, Mizuki Kato, et al. (2020) Temperature dependence and anisotropic effects in the thermal properties of hen egg-white lysozyme crystals. Symmetry 12 (8): 12081279.

16. JP Holman (1992) Heat transfer ( $7^{\text {th }}$ Edn.)., McGraw-Hill, London.

17. (2008) Japan Society of Thermophysical Properties. Thermophysical Properties Handbook. p. 72-75.

18. Park BK, Yi N, Park J, Kim D, (2013) Thermal conductivity of single biological cells and relation with cell viability. Appl Physs Lett. 102: 203702.

19. Babbit JD, (1945) The thermal properties of wheat in bulk. Canadian J Res Sec F 23: 388-401.

20. Bennett AH, Chance, WG, Cubbedge RH (1969) Heat transfer properties and characteristics of Appalachian area Red Delicious apples. ASHRAE Trans 75(2): 133

21. Chevalie D, Le Bail A, Ghoul M (2000) Freezing and ice crystals formed in a cylindrical food model: Part I. Freezing at atmospheric pressure. Journal of Food Engineering 46: 277-285.

22. Balasubramaniam TA, Bowman HF (1977) Thermal conductivity and thermal diffusivity of biomaterials: A simultaneous measurement technique. J Biomechanical Engineering-Transactions of the ASME 99(3): 148-154.

23. (2008) Japan Society of Thermophysical Properties. "Thermophysical Properties Handbook". pp. 579.

24. (2008) Japan Society of Thermophysical Properties. "Thermophysical Properties Handbook". pp. 579.

25. Ikezoe Y, Hirota N, Nakagawa J, Kitazawa K (1998) Making water levitate. Nature 393: 749-750.

26. Maki S, Oda Y, Ataka M (2004) High-quality crystallization of lysozyme by magneto-Archimedes levitation in a superconducting magnet. J Cryst Growth 261: 557-565.

27. Touloukian YS, De Witt DP (1970) Thermophysical Properties of Matter 2, Thermal conductivity. Nonmetallic solids, Plenum.

28. Touloukian YS, De Witt DP (1970) Thermophysical properties of M atter 5 , Specific heat, Nonmetallic solids, Plenum.

29. Chase MW, Davies CA, Downey JR, Frurip DJ, M cDonald RA, et al. (1985) JANAF Thermochemical Tables ( $3^{\text {rd }}$ Edn.)., Journal of Physical and Chemical Reference Data vol 14 Supplement.

30. Gane R (1936) The thermal conductivity of the tissue of fruits. Annual Report of the Food Investigation Board 5: 211-212. 
ISSN: 2574-1241

DOI: 10.26717 /BJSTR.2020.31.005090

Syou MAKI. Biomed J Sci \& Tech Res

(c) (P) This work is licensed under Creative (c) Commons Attribution 4.0 License

Submission Link: https://biomedres.us/submit-manuscript.php

$\begin{array}{ll}\text { BIOMEDICAL } & \text { Assets of Publishing with us } \\ \text { RESEARCHES } & \text { - Global archiving of articles } \\ \text { - Immediate, unrestricted online access }\end{array}$

